\title{
GCU
}

Glasgow Caledonian

University

University for the Common Good

\section{Domestic electricity load modelling by multiple Gaussian functions}

Ge, Yan; Zhou, Chengke; Hepburn, Donald

Published in:

Energy and Buildings

DOI:

10.1016/j.enbuild.2016.05.060

Publication date:

2016

Document Version

Author accepted manuscript

Link to publication in ResearchOnline

Citation for published version (Harvard):

Ge, Y, Zhou, C \& Hepburn, D 2016, 'Domestic electricity load modelling by multiple Gaussian functions', Energy and Buildings, vol. 126, no. 8, pp. 455-462. https://doi.org/10.1016/j.enbuild.2016.05.060

\section{General rights}

Copyright and moral rights for the publications made accessible in the public portal are retained by the authors and/or other copyright owners and it is a condition of accessing publications that users recognise and abide by the legal requirements associated with these rights.

Take down policy

If you believe that this document breaches copyright please view our takedown policy at https://edshare.gcu.ac.uk/id/eprint/5179 for details of how to contact us. 


\title{
Domestic electricity load modelling by multiple Gaussian functions
}

\author{
Yan Ge, Chengke Zhou, Donald M Hepburn, Glasgow Caledonian University, Glasgow, UK
}

\begin{abstract}
:
Domestic electricity load profile is essential for energy planning and renewable energy system design. This paper presents analysis of domestic electric load characteristics and a method to model domestic and regional load profile. Multiple Gaussian functions are used to express the load characteristics in the proposed model. This is done by associating the Gaussian function parameters with the peak load changes, e.g. changing height parameters to reflect the peak magnitude. The result of the load curve represented with multiple Gaussian functions allows the model to generate a regional load profile using the number of homes, the number of bedrooms $(\mathrm{Nr})$ and the number of occupants $(\mathrm{Np})$. The proposed model simulates domestic load profile by its load demand change characteristics instead of its appliance ownership and use pattern, etc. Data requirement for the proposed method is significantly lower than the previous top-down and bottom-up approaches. Seasonal change is not included in the present paper, but the method is capable of including seasonal changes if each season's load demand changes in relation to $\mathrm{Np}$ and $\mathrm{Nr}$ is available. A demonstration of modelling England and Wales's national hourly load profile in 2001 and 2011 is presented in this paper. Comparison is made of the proposed method with two other published domestic load profile models. Results show that the proposed method improves the mean percentage errors by at least $5.7 \%$ on average hourly load profile.
\end{abstract}

Key words: Electricity load modelling; Domestic load profiles; Energy-consumption; Energy planning; multiple Gaussian functions.

\section{Introduction:}

The growing interest in renewable energy and determination to reduce carbon emission has brought much attention to distributed generation and renewable system. Knowledge of domestic electricity load profile is essential for distributed generation system operation, renewable system design and energy planning. Domestic electricity load profile data is also required for planning low voltage networks in residential areas. The traditional domestic load modelling method often requires many input data to carry out modelling of the diversity of domestic load profile, e.g. time use of individual appliances. However such data may not be available or may be difficult to obtain at times. This paper presents a method using multiple Gaussian functions to express the load characteristics in order to reduce the data requirement for regional domestic load profile modelling.

In general, two approaches have been used in load profile modelling, Top-down and Bottom-up approaches. The Top-down approach works with macro situations and tries to attribute a load profile
52 to its modelling target with regard of its 53 characteristic [1], e.g. load change in relation to 54 income level, household size, etc. The Top-down 55 approach was also called Conditional Demand 56 Analysis by Aigner [2] and Parti [3] in 1980s. 57 Aigner used 24 regression equations to represent 58 each hour in a day, five scalar variables (number of 59 bedroom, internal temperature, etc.) and nine 60 dummy variables (presence and absence). The 61 energy demand of appliances is used to complete 62 the model. The key issue with Top-down models is 63 that they do not provide indication of variation 64 within family and home types, resulting in a lack of 65 detail on individual load characteristics. This is due 66 to lack of consideration of domestic load changing 67 characteristics in relation to scalar variables.

69 On the other hand the Bottom-up approaches are 70 built up from data on a hierarchy of disaggregated 71 components that are then combined according to 72 estimation for their individual impact on energy 73 usage [4]. The most commonly cited examples of 74 the Bottom-up models are Capasso [5], Paatero [6], 75 and Yao [7]. These models use data on ownership 76 of appliances, individual appliance energy demands, 77 and appliances usage time, to model the energy 
92 For practical regional load profile modelling, where

93 thousands of households need to be considered at

demand for a single household. As the authors addressed, the challenge of such modelling methods is the detailed data requirement in the range of households being considered, especially time of use of individual appliances: a complex and unpredictable human behavioural factor. Later models, e.g. Richardson [8] and Widén [9], use Time Use Survey (TUS) data to study behaviour factor in households. However, nation-wide TUS are conducted very rarely even in the developed countries, e.g. Richardson's model in year 2008 was based on year 2000 TUS report, which could result in inaccurate information being studied. once, the model must appropriately represent each type of household accordingly. It is, however, almost impossible to obtain detailed information and usage of every single household's appliances when dealing with large numbers of homes. Some domestic load profile models attempt to overcome the issue associated with input data requirement by generating domestic load profile from similar past load profiles, based on synthesising [10] and clustering [11] techniques. Such methods may not be able to model the future load changes, since they are purely based on past load profiles. Furthermore, the synthesising and clustering methods disconnect domestic load profile from behaviour and characteristics of domestic households, e.g. occupancy time, size of households. The methods may be suitable for certain applications, but they will not provide a better understanding of domestic energy consumption behaviour. Therefore, it is important to find a method to reduce data requirement on appliance ownership and use pattern for regional domestic load profile modelling.

This paper presents an alternative view on domestic load profile modelling, where morning and evening peak load have been considered as the most important characteristics of the domestic load profile. The model uses Gaussian function's bell shape to synthesise the morning and evening peak load profile. Instead of finding each appliance's impact on peak demand, the model considers number of household occupants $(\mathrm{Np})$ and number of bedrooms in the house $(\mathrm{Nr})$ as the two main drives of peak demand variation. $\mathrm{Nr}$ represents the impact of house size on peak load demand and $\mathrm{Np}$ considers how the number of occupants influences the peak load demand. Three Gaussian function parameters are associated with three aspects of peak load, where height parameters $(a)$ are used to synthesise peak magnitude, position parameters $(b)$ are used to synthesise peak load times, and width parameters $(c)$ are used to synthesise the peak duration.

The multiple Gaussian function model presented in this paper is based upon Yohanis's domestic electricity load characteristics study [12], where a household load profile was found to change with the number of persons and rooms. These factors are used to analyse domestic load characteristics.

\section{Methodology and Model structure:}

\subsection{Domestic electricity usage characteristics}

Yohanis's load characteristics study involved measurement of over 200 domestic households over a year. A sample of 27 households is selected to represent the whole population. The household types include detached, semi-detached, terraced homes and bungalow; the household size in terms of occupants includes 1 to $4+$; household size in terms of bedrooms includes 2 to 5 [12]. The study found that, although the magnitude of the average daily electricity load varied, the load profiles had very similar shapes for all measured households. The minimum load occurs during the night, between 2:00 and 4:00 a.m.; a minor (morning) peak occurs between 6:00 and 9:00 a.m. and a major (evening) peak occurs between 5:00 and 10:00 p.m. These periods show consistent similarity for all studied domestic households. Although the repeat pattern of morning and evening peak load are commonly mentioned in many load profile studies, this commonality of characteristics has not been used in domestic load profile modelling.

Figure 1 shows an example of modelling of domestic load profile by combining multiple Gaussian functions. The dotted lines with markers are the five Gaussian functions used to generate an overall load profile, shown as a solid line. The modelling process will be detailed in later sections. 


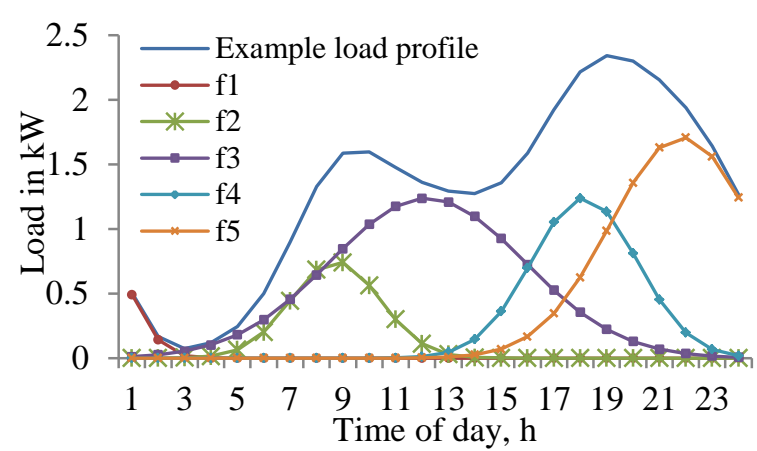

180 Figure 1: An example of using multiple Gaussian

181 functions (f1-f5) to model electricity load profile.

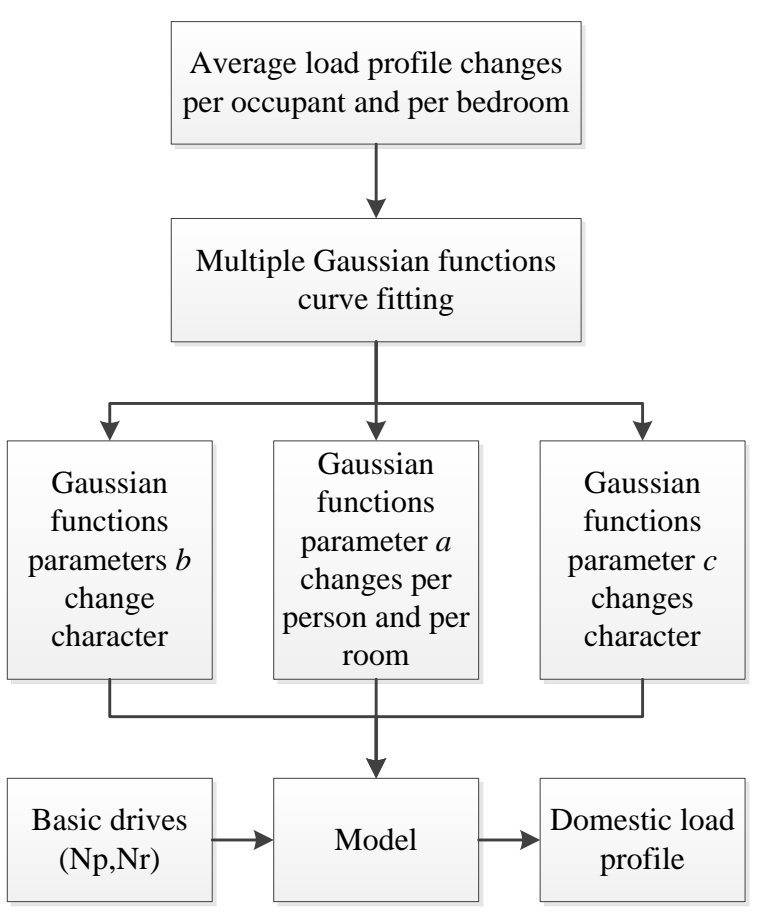

Figure 2: Flow chart of the proposed modelling process.

The flow chart of the proposed model is shown in Figure 2. The proposed model has dealt with the lack of measurement data by using Yohanis's measured load changes per occupant and per bedroom to analyse the Gaussian function parameter characteristics.

\subsection{Gaussian function fitting}

Figures 3 and 4, respectively, show the average domestic electricity load profile as a function of number of occupants and number of bedrooms. The data presented is calculated from Yohanis's study: average daily electricity consumption per unit floor area $\left(\mathrm{m}^{2}\right)$ as a function of number of occupants and bedrooms. The average size of standard buildings,

!04 from [13], is given in Table 1, average living space .05 per person (44 square metres) from [14]. Sizes of !06 households with 2 and 3 bedrooms are based on an !07 average size of flat and house from Table 1.

108

.09 Table 1: Domestic building average size in $\mathrm{m}^{2}$

\begin{tabular}{ll}
\hline Building types & $\begin{array}{l}\text { Average Size in } \\
\mathrm{m}^{2}\end{array}$ \\
\hline 1 Bedroom flat & 46.6 \\
2 Bedroom flat & 60.7 \\
3 Bedroom flat & 86.5 \\
1 Bedroom house & 64.3 \\
2 Bedroom house & 71.2 \\
3 Bedroom house & 95.6 \\
4 Bedroom house & 120.6 \\
5 Bedroom house & 163.5 \\
\hline
\end{tabular}

210

211 The average daily load variation per occupant and

212 per bedroom characteristics are contained in

213 Figures 3 and 4.

214

215 A domestic load profile can be represented by 216 equation (1), where $f_{1}, f_{2}, f_{3}, f_{4}$ and $f_{5}$ are the 217 Gaussian functions that build up the resultant load 218 profile.

219

$220 f_{\text {load }}=f_{1}+f_{2}+f_{3}+f_{4}+f_{5}$

221

222 where:

$223 f_{n}=\mathrm{a}_{n} \exp \left(-\frac{\left(\mathrm{x}-\mathrm{b}_{n}\right)^{2}}{2 \mathrm{c}_{n}{ }^{2}}\right)$

$224 n=1,2,3,4,5$

225 (a) accounts for peak load magnitude,

226 (b) accounts for peak load times,

227 (c) accounts for the peak duration

228 Five Gaussian functions are required in order to 229 keep parameter accuracy within 95\% of actual 230 results. The initial time parameter values are set as $2311,6,12,18$ and 23 to ensure that the five functions 232 are evenly distributed over 24 hours. The initial 233 values of magnitude and duration parameters are 234 set at zero.

235

236 Fitting of Gaussian curve functions is performed in 237 order to analyse those changing characteristics. The 238 Matlab curve fitting tool box is used to produce the 239 examples of fitting results in Figures 5 and 6. 


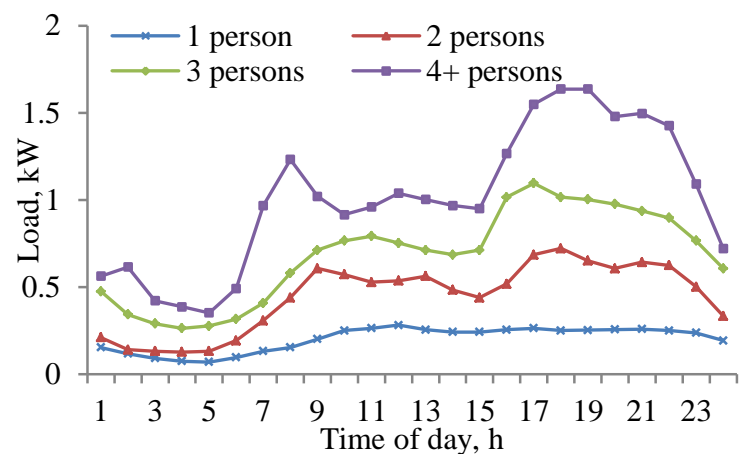

Figure 3: Average domestic electricity load profile as a function of number of occupants.

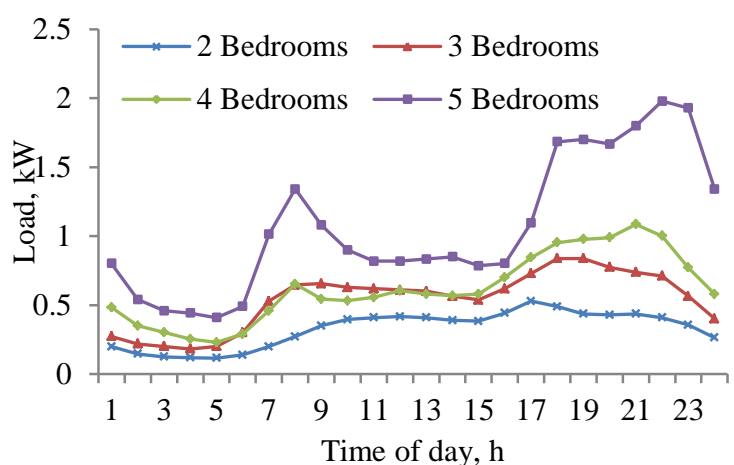

Figure 4: Average domestic electricity load profile as a function of number of bedrooms.

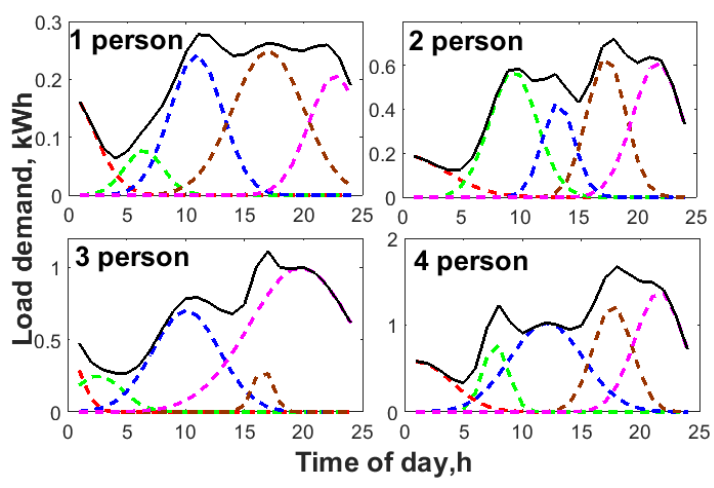

Figure 5: Curve fitting of number of persons to related load data with $95 \%$ confidence.

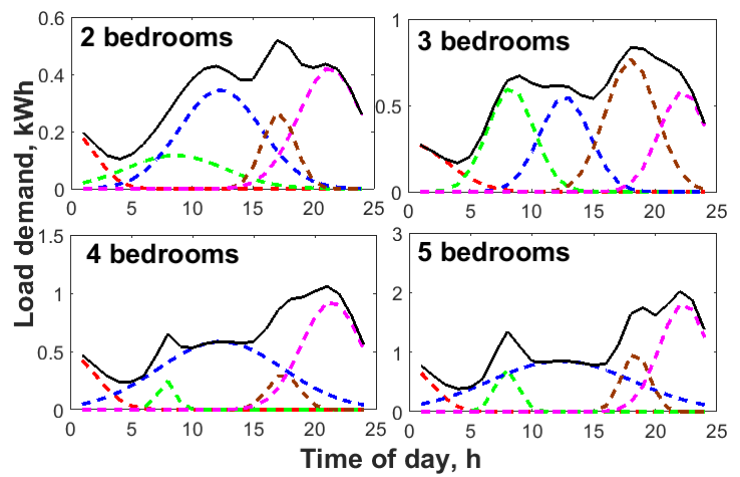

Figure 6: Curve fitting of number of bedrooms to related load data with $95 \%$ confidence.

\subsection{Parameter analysis}

This section presents the results of Gaussian functions fitting of 8 load profiles, shown in Figures 5 and 6.

There are 5 sets of Gaussian function parameter results from each of the 8 fitted load profiles. Each set of results contains the three Gaussian function parameters ( $a, b$ and $c$ ). The fitting of data in

267 In order to analyse the parameter change pattern in 268 relation to $\mathrm{Np}$ and $\mathrm{Nr}$, the 120 parameter results 269 have been categorised into three groups according 270 to type, i.e. 40 magnitude $(a), 40$ time $(b)$ and 40 271 duration (c) parameters. For each group the 40 272 values have been categorised by Gaussian function 273 order ( $\mathrm{n}=1$ to 5 ) and their relation to $\mathrm{Np}$ and $\mathrm{Nr}$.

274

275 Three analysis methods are used to find the 276 mathematical expression of the Gaussian function 277 parameters changing pattern, namely linear relation, 278 percentage of variations and probability density 279 function (PDF) fitting.

\section{2.3.1 Height parameter $a$}

282

283 Figures 7 and 8 show the values of 40 height 284 parameters in relation to $\mathrm{Np}$ and $\mathrm{Nr}$, respectively, 285 from Gaussian function fitting. The results show 286 that the magnitude parameter values increase as $\mathrm{Np}$ 287 and $\mathrm{Nr}$ increase. In general, Gaussian function 288 parameter $a$ has a linear relationship with $\mathrm{Np}$ and $289 \mathrm{Nr}$.

302

$a_{1}=(0.1439 N p-0.01695)+(0.1804 N r-$

303

0.02805 )

$304 \quad 0.06415)$

$a_{2}=(0.1439 N p-0.02909)+(0.142 N r+$

$305 a_{3}=(0.2618 N p-0.0534)+(0.1545 N r+$

306 0.1977) 
$307 a_{4}=(0.2616 N p-0.0457)+(0.176 N r+$

308 0.1497)

$309 a_{5}=(0.3912 N p-0.1749)+(0.4553 N r-$

310 0.1984)

311

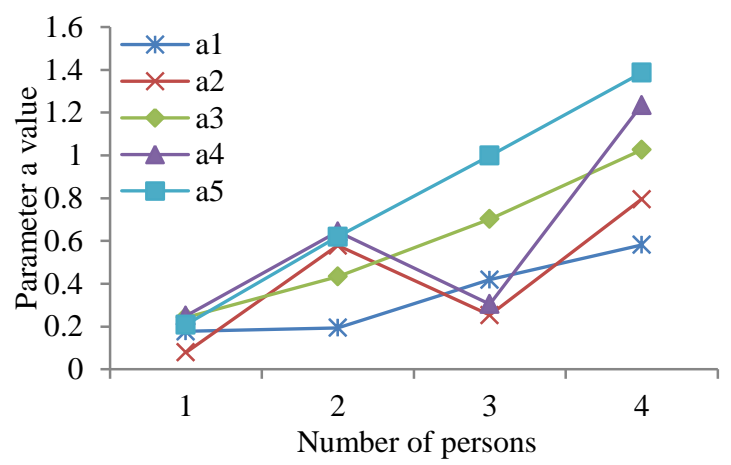

312

313 Figure 7: Magnitude parameter $a$ in relation to $\mathrm{Np}$

314

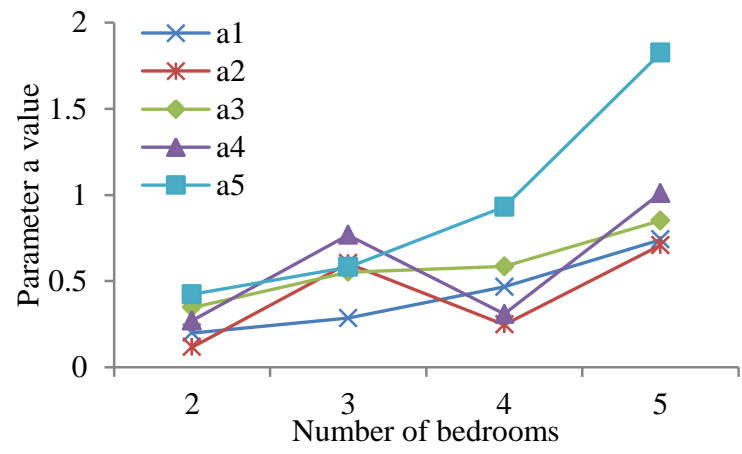

316 Figure 8: Magnitude parameter $a$ in relation to $\mathrm{Nr}$

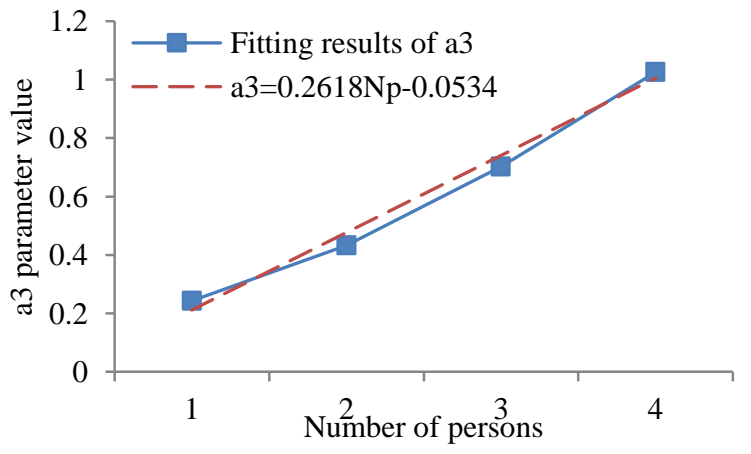

319 Figure 9: Magnitude parameter $\mathrm{a}_{3}$ results by $\mathrm{Np}$

320 and linear polynomial expression.

\section{2.3.2 Position parameter $b$}

323 Unlike the magnitude parameter, the time 324 parameter does not change much in relation to the 325 number of persons and bedrooms, as shown in 326 Figures 10 and 11. This is due to the fact that the 327 occupancy times of average households is mainly
328 defined by the working/school hours of the family 329 members. The increases in the numbers of $\mathrm{Np}$ and $330 \mathrm{Nr}$ have very little effect on this pattern. This is 331 because all occupants most likely have similar 332 working/school hours.

333

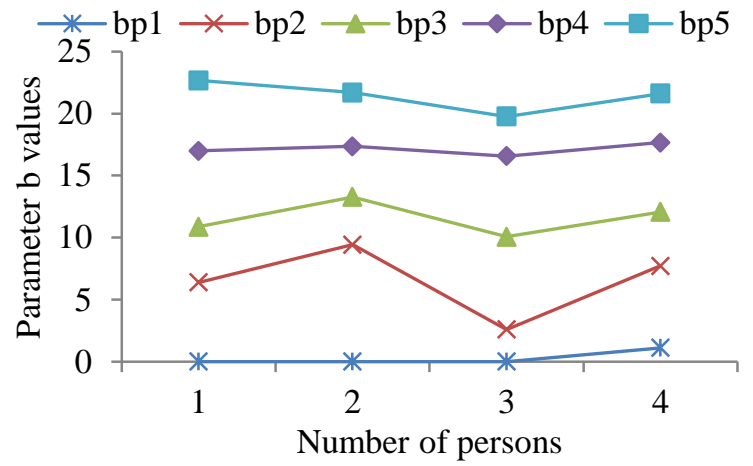

Figure 10: Time parameter $b$ in relation to $\mathrm{Np}$

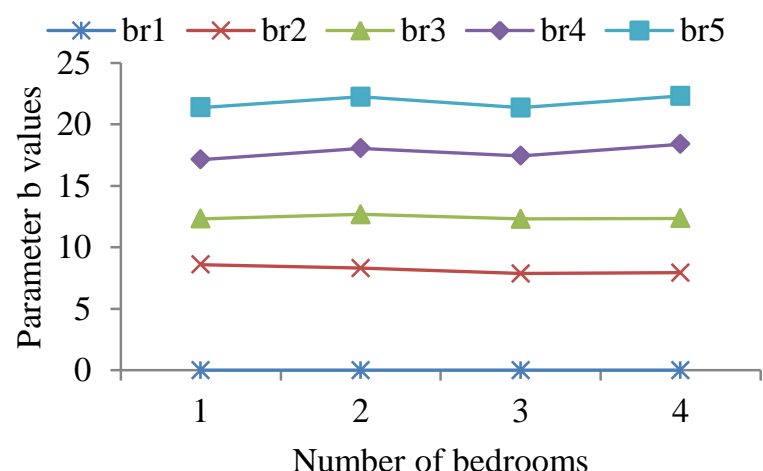

340 Therefore, the time parameter $b$ can be represented 341 as a mean value with random percentage variations, i42 as show in equation (7). Randomising the values i43 allows for variation in occupier's times of leaving i44 for work, coming home, etc.

145

146

i47

i48 where:

$\operatorname{mean}\left(b_{n}\right)=\operatorname{average}\left(b p_{n}+b r_{n}\right)$

;49

$\operatorname{var}\left(b_{n}\right)=\operatorname{mean}\left(\frac{b p_{n}-\operatorname{average}\left(b p_{n}\right)}{\operatorname{average}\left(b p_{n}\right)}+\right.$

$\left.350 \frac{b r_{n}-\operatorname{average}\left(b r_{n}\right)}{\text { average }\left(b r_{n}\right)}\right) \%$

$n=1,2,3,4,5$

351 random: A random value is generated between 0

352 to $\operatorname{var}\left(b_{n}\right)$

353

354

355 2.3.3 Duration parameter $c$ 
357 The changes in the pattern of duration parameter in 358 relation to $\mathrm{Np}$ and $\mathrm{Nr}$ are shown in Figures 12 and 359 13. The duration parameters $c$ do not appear to 360 have a constant relation to $\mathrm{Np}, \mathrm{Nr}$.

361

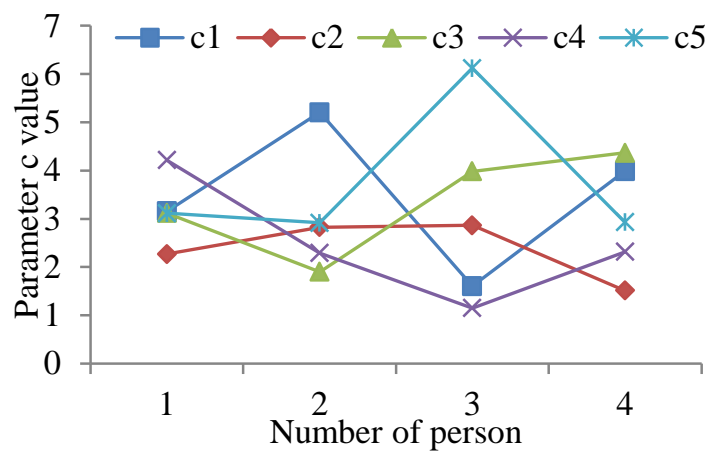

363 Figure 12: Duration parameter $\mathrm{c}$ in relation to $\mathrm{Np}$

364

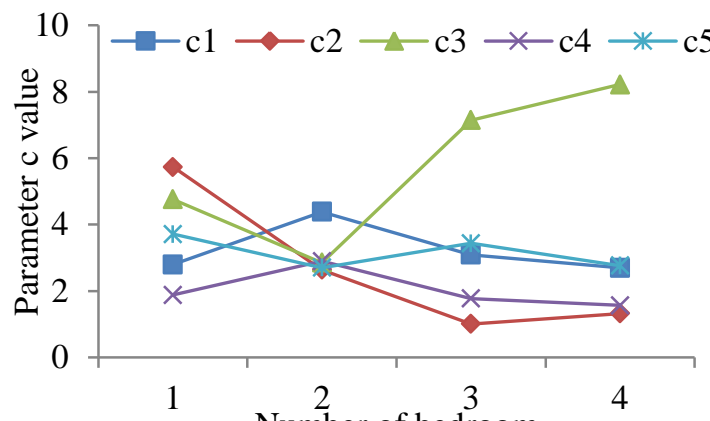

366 Figure 13: Duration parameter c in relation to $\mathrm{Nr}$

367

368 Therefore the model assumes that the duration

369 parameter has a random value with certain type of

370 probability density function (PDF). The 40 width

371 parameter $c$ values shown in Figures 12 and 13 are

372 categorised by its number of appearances in Figure

373 14. The PDF fitting result of 40 duration parameter

374 values are shown in Figure 15, the lognormal PDF

375 has the best fit with mean value $(m) 3.24421$ and

376 variance value $(v) 2.67782$. Equation 8 is used to

377 generate a random value of width parameter $c$ for

378 the model.

$379 c_{n}=\operatorname{random}\left(\frac{1}{x \sigma \sqrt{2 \pi}} e^{-\frac{(\ln (x)-\mu)^{2}}{2 \sigma^{2}}}\right)$

380

381 where:

$\mu=\log \left(\frac{m^{2}}{\sqrt{v+m^{2}}}\right)$
$\sigma=\sqrt{\log \left(\frac{v}{m^{2}}+1\right)}$

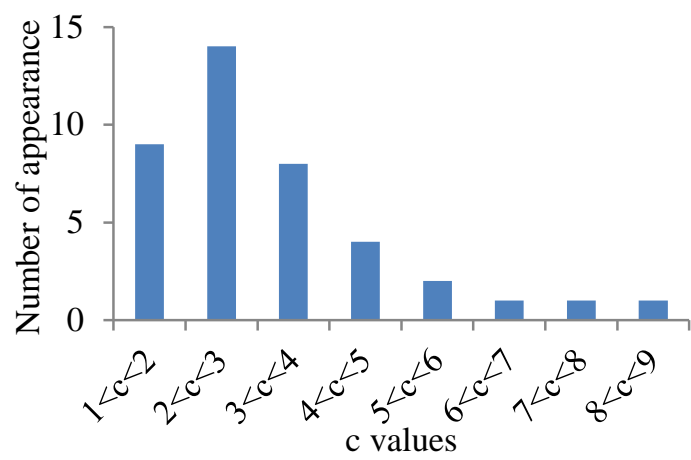

388 Figure 15: PDF fitting for duration parameter.

A single household load profile formula is shown in equation (9).

$f_{(N p, N r)}=\sum_{n=1}^{n=5}\left(\mathrm{a}_{n} \exp \left(-\frac{\left(\mathrm{x}-\mathrm{b}_{n}\right)^{2}}{2 \mathrm{c}_{n}{ }^{2}}\right)\right)$

395

396

397

398

399

$$
f=\sum_{1}^{m}\left(N_{p}, N_{r}\right) \cdot f_{(N p, N r)}
$$

400

401 where:

$402 m$ is number of households in the region

403

404

405

406 England and Wales's national domestic electricity

407 load profile in 2001 and 2011 have been modelled

408 in this case study. This case only considers the 
impact of population changes on national domestic

412 households in England and Wales to be 21.66

413 million in 2001 and 23.366 million in $2011[15,16]$.

414 The total number of households increased by $7.87 \%$

415 (1.706 million) in a decade

416

417

418

419

420

421

422

423

424

425

426

427

428

429

430 where:

$431 M$ is number of family groups

$432 P$ is household size by number of people

$433 \mathrm{~S}$ is state of a household (Owner $j=1$, Rented $j=2$ )

$434 \mathrm{R}$ is household size by number of bedrooms

435

436 The number of households for each group can be

437 calculated from the values provided in Table 2-5.

438 Equation 12 shows an example of the calculation of

439 the number of households which are 2 people, 3

440 bedrooms, owner occupied in year 2011.

441

442

$N_{\left(P_{(i)}, S_{(j)}, R_{(k)}\right)}=T \cdot P_{(2)} \cdot S_{(2)} \cdot R_{(3)}=2.69 \times 10^{6}$

443 where:

$444 T$ is equal to 23.366 million (total number of

445 households in year 2011)

$446 P_{(2)}$ 's value is 0.36 from Table $2,2^{\text {nd }}$ row in 2011

447 column.

$448 S_{(2)}$ 's value is 0.64 from Table $3,1^{\text {st }}$ row in 2011

449 column

$450 R_{(3)}$ 's value is 0.5 from Table $4,2^{\text {nd }}$ row $3^{\text {rd }}$ column

451 (the rented household should look up $R$ 's value in

452 Table 5)

453

454

455

456
457 Table 2: Percentage of Household by people in

458 England and Wales, 2001 and 2011[15, 16].

\begin{tabular}{|c|c|c|}
\hline Number of people in household & 2001 & 2011 \\
\hline 1 person & $32 \%$ & $29 \%$ \\
\hline 2 people & $34 \%$ & $36 \%$ \\
\hline 3 people & $15 \%$ & $16 \%$ \\
\hline 4 people & $13 \%$ & $13 \%$ \\
\hline 5 people & $5 \%$ & $4 \%$ \\
\hline 6 or more people & $2 \%$ & $2 \%$ \\
\hline
\end{tabular}

459

460 Table 3: Percentage of Home Ownership and

461 Renting [17]

\begin{tabular}{lll}
\hline House Ownership and Renting & $\mathbf{2 0 0 1}$ & $\mathbf{2 0 1 1}$ \\
\hline Owner Occupied & $69 \%$ & $64 \%$ \\
Rented & $31 \%$ & $36 \%$ \\
\hline
\end{tabular}

462

463 Table 4: Percentage of Owner occupied households,

464 by size and number of bedrooms in 2011 [18]

\begin{tabular}{lrrrrr|l}
\hline \multicolumn{1}{c}{ Bedroom } & 1 & 2 & 3 & 4 & $5+$ & SUM \\
People & & & & & & \\
\hline 1 & $10 \%$ & $35 \%$ & $45 \%$ & $8 \%$ & $2 \%$ & $100 \%$ \\
2 & $2.5 \%$ & $25 \%$ & $50 \%$ & $17.5 \%$ & $5 \%$ & $100 \%$ \\
3 & $0.5 \%$ & $15 \%$ & $54.5 \%$ & $24 \%$ & $6 \%$ & $100 \%$ \\
4 & $0 \%$ & $7 \%$ & $53 \%$ & $32 \%$ & $8 \%$ & $100 \%$ \\
5 & $0 \%$ & $4 \%$ & $41 \%$ & $39 \%$ & $16 \%$ & $100 \%$ \\
$6+$ & $0.5 \%$ & $2.5 \%$ & $32 \%$ & $39 \%$ & $26 \%$ & $100 \%$ \\
\hline
\end{tabular}

465

466 Table 5: Percentage Rented household, by size and

467 number of bedrooms in 2011 [18]

\begin{tabular}{lrrrrr|r}
\hline \multicolumn{1}{c}{ Bedroom } & 1 & 2 & 3 & 4 & $5+$ & SUM \\
People & & & & & & \\
\hline 1 & $51 \%$ & $32 \%$ & $13 \%$ & $3 \%$ & $1 \%$ & $100 \%$ \\
2 & $20 \%$ & $49 \%$ & $27 \%$ & $3.5 \%$ & $0.5 \%$ & $100 \%$ \\
3 & $6 \%$ & $41 \%$ & $45 \%$ & $6 \%$ & $2 \%$ & $100 \%$ \\
4 & $2.5 \%$ & $28 \%$ & $55 \%$ & $12 \%$ & $2.5 \%$ & $100 \%$ \\
5 & $2 \%$ & $16 \%$ & $57 \%$ & $17 \%$ & $8 \%$ & $100 \%$ \\
$6+$ & $2 \%$ & $9 \%$ & $48 \%$ & $24 \%$ & $17 \%$ & $100 \%$ \\
\hline
\end{tabular}

468

469

470

471

472

473

474

475

476

477

478

479

480

481

482

483

484

485
For the case study, as the 2001 census report did not provide information related to the size and number of bedrooms, the percentage in each classification for 2001 is assumed to be the same as that in 2011.

\subsection{Results and validation}

3.2.1 Examples of individual family household load profile

Ten load profile examples are shown in Figures 16 and 17. Figure 16 includes five examples of electricity load of one person living in one bedroom. Figure 17 shows results of five load profiles of three persons living in two bedroom accommodation. Each example is different because of the random values used for Gaussian function 
498 Comparison between Figures 16 and 17 shows the

519 This similar load changing character can also be

520 found in the England and Wales's national

521 electricity load (includes domestic, commercial and

Figure 17: 5 Load demand profile of 3 persons in 2 bedroom accommodation peak loads have increased, as expected, with changes in $\mathrm{Np}$ and $\mathrm{Nr}$. Figures 16 and 17 share similar load characteristics to measurement results in Figures 3 and 4, e.g. low activity level in early morning and late evening, increase in electricity demand during the two peak periods, etc.

\subsubsection{England and Wales national load model} results for Year 2001 and 2011

Modelling results of hourly domestic electricity use in England and Wales in 2001 and 2011 are presented in Figure 18. The model results for both years have a very similar shape. The 2011 average load magnitude increased smoothly between 7 a.m. and 10 p.m. The mid-night time has not changed much, this is because the population increase would not change the fact people do not consume much electrical power during mid-night hours. industry) in Figure 19, where the overall electricity consumption behaviour did not change much over the years. The mid-night load increase in Figure 19 is because many commercial and industrial energy users still consumed electricity during the midnight time. Figure 19 also shows a decrease of electricity load demand from 2006 to 2011. The model, as shown in Figure 18, failed to represent this decrease in electricity load demand. This is because there is only one year's data on load demand in relation to the number of occupant (Np) and bedrooms (Nr) data used for load characteristics analysis. This could be improved when multiple years' average load becomes available for load characteristics analysis.

The modelling results suggest that the population and number of households have very little impact on national domestic electricity load profiles in terms of load shapes over the ten year period investigated. Comparison of the modelling and real data indicates that energy efficiency and other measures have a much greater impact on energy demand than population changes.

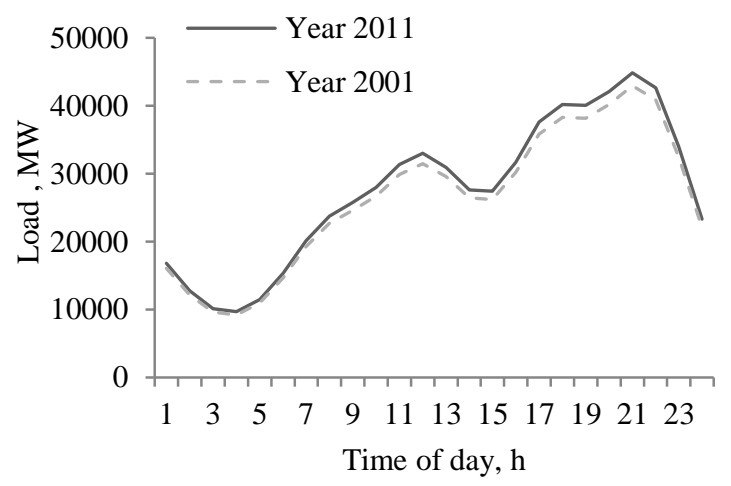

547
548 549 550
England and Wales's electricity load.

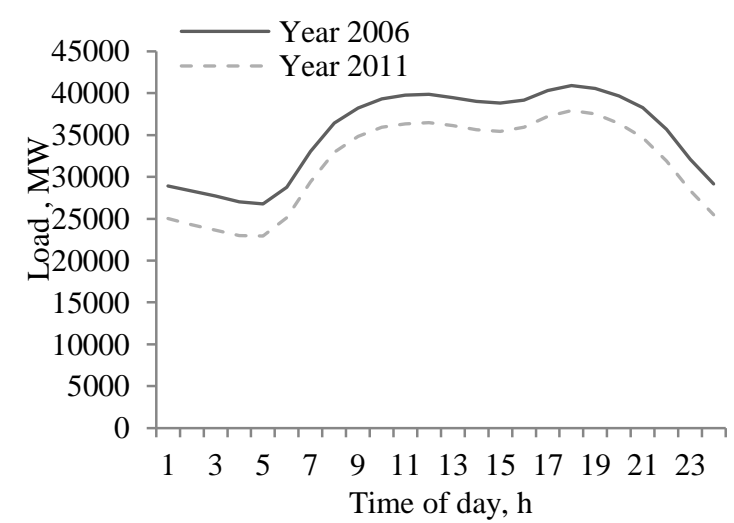

Figure 19: England and Wales's national electricity load 2006 and 2011 [19]. 


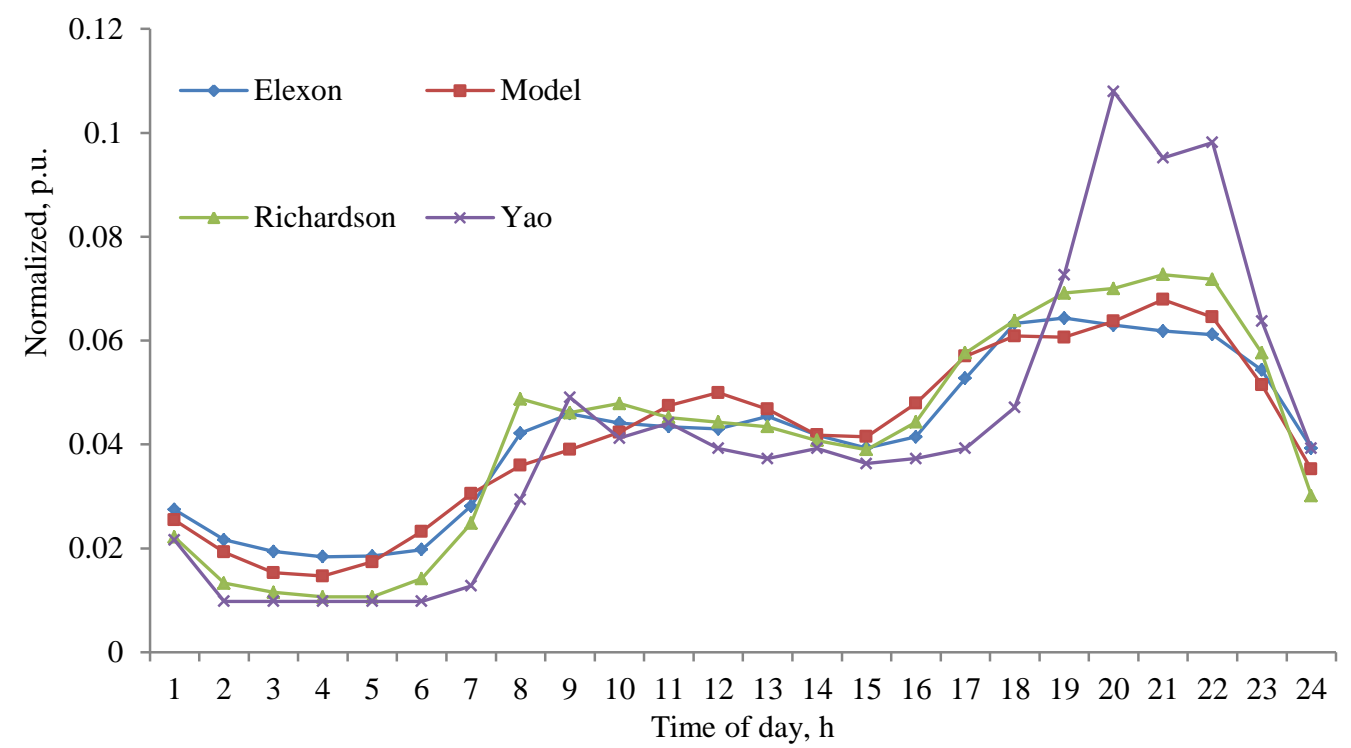

568 MPE $=\frac{100 \%}{\mathrm{n}} \sum_{\mathrm{t}=1}^{\mathrm{n}} \frac{\left|\mathrm{m}_{\mathrm{t}}-\mathrm{a}_{\mathrm{t}}\right|}{\mathrm{a}_{\mathrm{t}}}$

569 where:

$570 \mathrm{~m}_{\mathrm{t}}$ is the modelled load result,

$571 \mathrm{a}_{\mathrm{t}}$ is the comparison target result,

$572 \mathrm{n}$ is number of time intervals. Here $\mathrm{n}=24$.

573

574 The result shows that the model presented in this

575 paper has the lowest MPE 9.4\% in comparison with

576 Richardon's $15.1 \%$ and Yao's $28.6 \%$. This shows a

$5775.7 \%$ improvement over the past models. The

578 proposed model has the closest match on evening

579 peak load demand and on early morning load,

580 between $1 \mathrm{AM}$ and $6 \mathrm{AM}$. The proposed method did

581 not have the best result on morning peak load, as it

582 has a later morning peak time than others. The

583 cause of this will be discussed in the next section.

584

585 In addition to having greater overall accuracy, the

586 proposed model also uses less input data. Firstly,

587 both Yao and Richardson's models required data

588 on appliances ownership, whereas the proposed

589 model does not need to know any details on

590 appliances. Secondly, Richardson's model used

591 TUS data as input, which is much more complex
592 than Yohanis's 27 household electrical load 593 measurements.

594

595 The model proposed in this paper made it possible 596 to model national domestic electricity load profile 597 characteristics from a small number of 598 measurement results combined with the national 599 census data. The simplicity of this method makes it 600 possible to apply it to situations where there is a 601 lack of domestic load profile statistical data.

602

603 3.2.4 Characteristics, reference and model result 604 data comparisons

605

606 In order to explain why the model did not produce

607 a better result during morning peak period, a

608 comparison between total average load of

609 Yohanis's characteristic study, Elexon reference

$610 \mathrm{load}$ and the model's result is shown in Figure 21.

611

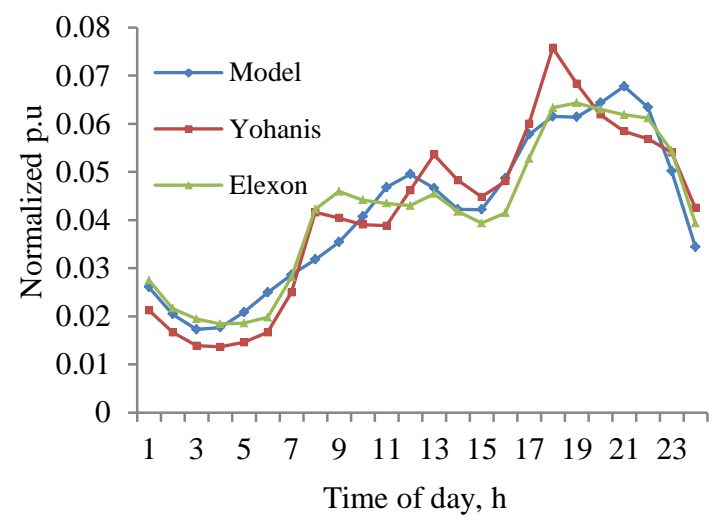

613 Figure 21: Yohanis study's average load profile in 614 comparison to model result and Elexon's reference 615 load. 
617 This shows the Yohanis average domestic load 618 profile has a much later morning peak time 619 compared with the reference load. The position 620 parameter $b$ analysis process picked up this late 621 morning peak time characteristics from Yohanis's 622 data. This could be caused by the fact that Yohanis 623 study only measured 27 households, where the 624 small number of individual families had too much 625 impact on average load profile. On the other hand, 626 it also demonstrated that the proposed method is 627 very effective in capturing the characteristic 628 information from the measured data.

\section{Conclusions and Discussions:}

This paper introduced a novel method for determining regional electrical load through a minimum amount of information. The application of a multiple Gaussian function based method to model domestic household electricity load profile using the number of households in a region. Input data uses readily available information, or that which could be estimated for a proposed housing development, i.e. the number of persons $\mathrm{Np}$ and bedrooms and $\mathrm{Nr}$ of the households. The presented model is based on Yohanis's domestic load profile characteristic study. Other domestic load studies based on measurement result with load changes per occupant and per bedroom can also serve the same purpose. Gaussian function curve fitting are used to analyse the load characteristic variation with $\mathrm{Np}$, Nr.

This paper provided insights to the characteristics using mathematical expressions which are then integrated into a load profile model to generate synthetic data. The model is capable of generating a regional load profile with different household composition and population, assuming the analysis target have similar load characteristics. The method can also effectively represent the national electricity characteristics from measurement results of small number of household (27 household).

The model could be improved in two of the following areas:

I) Improve domestic load profile characteristic study: i) The method will benefit from more detailed characteristic study, e.g. mid-day load change characteristics per occupant and per bedroom. ii) Increasing the number of households measured in the characteristic study will also improve the model accuracy, e.g. the late morning peak in Yohanis's study leads to errors in the modelling result. iii) Better categorisation of the measured households could improve the model result, e.g. Yohanis's study only provided average load profile changes per occupants and bedrooms, by providing different type of household load profile changes per occupant and bedroom would improve the variety and accuracy of the model result. iv) Seasonal load profile change can be included in the model if each season's load change per occupant and per bedroom is provided in load characteristics study.

II) Further Gaussian parameters analysis: some Gaussian parameter relations to the $\mathrm{Np}$ and $\mathrm{Nr}$ require further investigation. i) The magnitude parameter values (a2, a4) drop at 3 person and 4 bedrooms, shown in Figures 6 and 7 . ii) The unusual duration parameter changes with three bedroom households in Figure 11. These indicate that certain types of family may require additional analysis. Increasing the number of data points for duration parameter will give a more complete picture of duration parameter characteristics and better analysis result.

\section{Reference:}

[1] A.Grandjean, J.Adnot, G.Binet, A review and analysis of the residential electric load curve models, Renewable and Sustainable Energy Review 16 (2012) 6539-6565

[2] D.Aigner, C.Sorooshian, P.Kerwin, Conditional demand analysis for estimating residential end-use load profiles. The Energy Journal 1984; 5(3):81-97

[3] M.Parti, C.Parti, The total and appliance-specific conditional demand for electricity in the household sector. Bell Journal of Economic 1980;11(1):309-21

[4] M.Kavgic, A.Mavrogianni, D.Mumovic, A.Summerfield, et al, A review of bottom-up building stock models for energy consumption in the residential sector; Building and Enviorments 45 (2010) 1683-1697

[5] A. Capasso, W. Grattieri, R. Lamedica, and A. Prudenzi, Bottom-up approach to residential load modeling, IEEE Trans. Power Syst., vol. 9, pp. 957964, 1994.

[6] J. V. Paatero and P. D. Lund, A model for generating household electricity load profiles, Int. J. Energy Res., vol. 30, pp. 273-290, 2006.

[7] R. Yao and K. Steemers, A method of formulating energy load profile for domestic buildings in the UK, Energy Build., vol. 37, pp. 663-671, 2005.

[8] I. Richardson, M. Thomson, D. Infield, and C. Clifford, Domestic electricity use: A high-resolution energy demand model, Energy Build., vol. 42, pp. 1878-1887, 2010.

[9] J. Widén and E. Wäckelgård, A high-resolution stochastic model of domestic activity patterns and electricity demand, Appl. Energy, vol. 87, pp. 18801892, 2010. 
[10] D.P.Jenkins, S.Patidar, S.A.Simpson, Synthesising electrical demand profiles for UK dwellings. Energy and Buildings76 (2014) 605-614, doi:10.1016/j.enbuild.2014.03.012

[11] F. Mcloughlin, A.Duffy, M.Conlon, A clustering approach to domestic electricity load profile characterisation using smar metering data, Apply $\begin{array}{llll}\text { energy } & 141 & \text { (2015) } & 190-199\end{array}$ doi:10.1016/j.apenergy.2014.12.039

[12] Y. G. Yohanis, J. D. Mondol, A. Wright, and B. Norton, Real-life energy use in the UK: How occupancy and dwelling characteristics affect domestic electricity use, Energy Build., vol. 40, pp. 1053-1059, 2008.

[13] Housing standards: evidence and research dwelling size survey. A report prepared by Scott Wilson for CABE, April 2010.

[14] K. Williams, Space per person in the UK: A review of densities, trends, experiences and optimum levels, Land Use Policy 26S (2009)S83-S92

[15] Office for National Statistics, English Housing Survey: Households 2010-11. Office National Statistics, July 2012

[16] Office for National Statistics, Living in Britain: Result from the 2000/01 General Household Survey, 2001

[17] Office for National Statistics, A Century of Home Ownership and Renting in England and Wales (Full story), Part of 2011 Census Analysis, 19th April 2013

[18] Office for National Statistic, Home ownership and renting in England and Wales- Detailed Characteristics, Part of 2011 Census, Detailed characteristics on Housing for Local Authorities in England and Wales Release 28th June 2013

[19] NationalGrid, DemandData_historic 2006 and 2011, http://www2.nationalgrid.com/UK/Industryinformation/Electricity-transmission-operationaldata/Data-Explorer/ last review in $06^{\text {th }}$ December 2015

[20] ELEXON, Load profiles and their use in Electricity Settlement version 2.0, $7^{\text {th }}$ November 2013. 